\title{
Presence of Macrophage Migration Inhibitory Factor in Human Milk: Evidence in the Aqueous Phase and Milk Fat Globules
}

\author{
BARBARA MAGI, FRANCESCA IETTA, ROBERTA ROMAGNOLI, SABRINA LIBERATORI, \\ VITALIANO PALLINI, LUCA BINI, SERGIO A. TRIPODI, MARCELLA CINTORINO, \\ FRANCESCA CHELLINI, FELICE ARCURI, CLAUDIO DE FELICE, AND LUANA PAULESU
}

Departments of: Molecular Biology, [B.M., S.L., V.P., L.B.], and Pediatrics, Obstetrics and Reproductive Medicine [C.D.F.]; Institutes of: General Physiology [F.I., R.R., F.C., L.P.]; and Pathological Anatomy and Histology, [S.A.T., M.C., F.A.]; University of Siena, 53100 Siena, Italy

\begin{abstract}
ABS
Human milk is a source of bioactive substances regulating the
development and activity of the newborn immune system. Hu-
man milk has been found to contain a number of cytokines,
including interleukins, growth factors, and colony stimulating
factors. In the present study, we assessed 10 specimens of human
milk for the presence of macrophage migration inhibitory factor
(MIF), a cytokine recently described in several human reproduc-
tive organs and tissues. Using biochemical as well as immuno-
logic techniques, we showed that MIF is abundantly present in
human milk, mostly distributed in the lipid layer and in the
aqueous phase. Fractionation of the lipid layer showed that MIF
is highly concentrated inside milk fat globules. In view of its
\end{abstract}
proinflammatory features, we speculate that milk MIF may protect the newborn against infection and play a role in preserving the functionality of the lactating mammary gland. Furthermore, the localization of MIF in lipid globules suggests a possible strategy for the protection of milk cytokines from the gastric barrier. (Pediatr Res 51: 619-624, 2002)

\section{Abbreviations}

MIF, macrophage migration inhibitory factor

MFG, milk fat globules

MFGM, milk fat globule membranes

TBS, Tris-buffered saline
Human milk is a complex biologic fluid that supplies nutritional and protective factors to the breast-fed infant. It contains a wealth of immunologically active components involved in the innate and acquired immune response against infectious agents and antigenic stimuli (1). Indeed, a number of cytokines have been described in human milk in the past $20 \mathrm{y}(2)$. These include proinflammatory (tumor necrosis factor- $\alpha$, IL- $1 \beta$, IL-6, IL-8, IL-12, and $\gamma$-interferon) (3-6) and antiinflammatory cytokines (transforming growth factor- $\beta$, IL-10) $(7,8)$, and, as recently reported, colony-stimulating factors (granulocyte colony-stimulating factor, macrophage colony-stimulating factor, and granulocyte-macrophage colony-stimulating factor) (911). Taken together, these data strongly suggest that most cytokines are provided to the newborn, potentially affecting the development and functions of the immune system.

MIF is a cytokine originally identified as a factor released by activated $\mathrm{T}$ lymphocytes capable of inhibiting the random

Received July 13, 2001; accepted December 20, 2001.

Correspondence and reprint requests: Luana Paulesu, Ph.D., Institute of General Physiology, Via A. Moro, 53100 Siena, Italy; e-mail: paulesu@unisi.it

Supported by a research grant from the Italian Ministry of Education MURST (Founding for Research of National Institute) and from the University of Siena. migration of macrophages in vitro (12). Later, it became evident that besides $\mathrm{T}$ cells, monocytes and macrophages produce MIF that is released in response to proinflammatory stimuli, such as microbial toxins, mitogens, specific antigens, or cytokines (tumor necrosis factor- $\alpha$ and $\gamma$-interferon), and to physiologic concentration of glucocorticoids (13-15). Emerging evidence demonstrates MIF expression by a number of human cells other than lymphocytes and macrophages. For instance, MIF protein and mRNA have been detected in the differentiating cells of eye lens, as well as in the human cornea, skin, and kidney (16-19). Previous data from our laboratory have demonstrated MIF expression in human reproductive organs and tissues, including the mammary gland (20-22). Furthermore, MIF has been reported to be secreted by a variety of cell types such as pituitary, adipocytes, testis, epithelial prostatic, and endometrial cells (23-26).

In the study reported herein we tested the hypothesis that MIF is present in human milk. We speculated that in view of its proinflammatory features and action on macrophages, milk MIF may affect the development of the newborn immune system and may play a role in preserving the functionality of the lactating mammary gland. 


\section{METHODS}

Sample collection. Peripheral blood $(3 \mathrm{~mL})$ and milk samples $(20 \mathrm{~mL})$ were collected from 10 healthy women (ages 25-33 y) who had delivered normal full-term infants by spontaneous active labor. In particular, no subjects had signs of uterine infection or breast inflammatory diseases. Samples, obtained on postpartum d 5, were collected in sterile polypropylene tubes, and processed within $1 \mathrm{~h}$. The study was approved by the Clinical Investigations Committee at the University of Siena, and informed consent was obtained from each subject.

Sample processing. Blood was centrifuged at $3,000 \times g$ for $30 \mathrm{~min}$ at $4^{\circ} \mathrm{C}$, and serum aliquots were stored at $-80^{\circ} \mathrm{C}$ until assayed. An aliquot of breast milk was processed for twodimensional electrophoresis, SDS-PAGE, and immunoblotting. The remainder was fractionated according to the protocol of Basch et al. (27). Briefly, milk was centrifuged at $5000 \times g$ for $15 \mathrm{~min}$ at $25^{\circ} \mathrm{C}$ to obtain a pellet containing milk cells, an aqueous phase, and a floating lipid layer, containing MFG. The lipid layer was gently suspended in $10 \mathrm{mM}$ PBS (pH 7.4), and stored at $5^{\circ} \mathrm{C}$ overnight. It was then churned with a Turrax (IKA Labortechnik, Staufen, Germany) at a medium speed until fat and sera were separated. After a brief warming at $40^{\circ} \mathrm{C}$, specimens were centrifuged at $100,000 \times g$ for $1 \mathrm{~h}$ at $37^{\circ} \mathrm{C}$ to obtain a pellet containing crude MFGM, an aqueous phase (MFG aqueous phase), and a lipid phase. Aliquots of lipid layer were centrifuged at $700 \times g$ onto glass slides using a cytospin centrifuge and immediately fixed and used for immunohistochemistry.

Gel electrophoresis and immunoblotting. SDS-PAGE was performed according to Laemmli (28). Electrophoresis was performed on $16 \%$ polyacrylamide gels. Protein concentration was estimated using the method of Bradford (29). Twodimensional electrophoresis was carried out on milk samples as described by Görg et al. (30) and modified by Bjellqvist et al. (31). An aliquot of $34 \mu \mathrm{L}$ of milk was mixed with $17 \mu \mathrm{L}$ of a solution containing SDS $10 \%(\mathrm{wt} / \mathrm{vol})$ and dithioerythritol $2.3 \%(\mathrm{wt} / \mathrm{vol})$. The sample was heated to $95^{\circ} \mathrm{C}$ for $5 \mathrm{~min}$ and then diluted to $500 \mu \mathrm{L}$ with a solution containing $8 \mathrm{M}$ urea, 3-[(3-cholamidopropyl)dimethyl-ammonio]-1-propanesulfonic acid 4\% (vol/vol), $40 \mathrm{mM}$ Trizma base, $65 \mathrm{mM}$ dithioerythritol, and a trace amount of bromophenol blue (denaturing solution). The isoelectric focusing (first dimension) was carried out on a commercial sigmoidal immobilized $\mathrm{pH}$ gradient (IPG), from $\mathrm{pH} 3$ to 10 (NL18-cm long IPG strips; Pharmacia, Uppsala, Sweden). The second dimension was performed on 9 to $16 \%$ polyacrylamide gradient gel. The gel was stained with ammoniacal silver nitrate as described (32). Electrophoretic images were digitized using the Molecular Dynamics Amersham Biosciences, Uppsala, Sweden computing densitometer $(4000 \times 5000$ pixels; 12 bits/pixel), and analyzed with the Melanie II (Bio-Rad Laboratories, Milan, Italy) software on a SUN SPARC station 10; gel calibration was carried out on the basis of internal standards. The Expasy World Wide Web molecular biology server of the Geneva University Hospital and of the University of Geneva was applied to predict $M_{\mathrm{r}}$ and pI for human MIF. Protein electroblotting was carried out following the procedure of Towbin et al. (33). Goat polyclonal antibody against human MIF (R\&D Systems, Abingdon, U.K.) was used at 1:1000 working dilution. For detection, a chemiluminescence kit (Amersham Pharmacia Biotech International, Little Chalfont, U.K.) was used according to the manufacturer's instructions.

MIF ELISA. Samples of blood serum and the aqueous phases obtained by the centrifugation of milk (milk aqueous phase) and by processing the lipid layer (MFG aqueous phase) were assayed using a quantitative colorimetric sandwich ELISA. Briefly, 96-well ELISA plates were coated with 100 $\mu \mathrm{L} /$ well of anti-human MIF MAb (R\&D Systems; $2.0 \mu \mathrm{g} / \mathrm{mL}$ ) and incubated overnight at room temperature. The plates were washed three times with washing solution [10 mM PBS (pH $7.4), 0.05 \%$ (vol/vol) Tween 20], blocked by adding $300 \mu \mathrm{L}$ of blocking solution [10 mM PBS (pH 7.4), 1\% (wt/vol) BSA, and $5 \%(\mathrm{wt} / \mathrm{vol})$ sucrose], and incubated at room temperature for $1.5 \mathrm{~h}$. After washing three times, the samples and the standard, appropriately diluted in TBS-BSA [20 mM Tris- $\mathrm{HCl}$, $150 \mathrm{mM} \mathrm{NaCl}$, (pH 7.3), $0.1 \%$ (wt/vol) BSA, $0.05 \%$ (vol/vol) Tween 20], were added in duplicate (100 $\mu \mathrm{L} /$ well) and incubated for $2 \mathrm{~h}$ at room temperature. Plates were then washed three times, and $100 \mu \mathrm{L}$ of biotinylated goat anti-human MIF antibody (R\&D Systems; $200 \mathrm{ng} / \mathrm{mL}$ ) was added to each well and incubated for $2 \mathrm{~h}$ at room temperature. Plates were washed again, and streptavidin-horseradish peroxidase (Zymed, San Francisco, CA, U.S.A.) was added to each well and incubated for $20 \mathrm{~min}$ at room temperature. The plates were washed, and 3,3',5,5'-tetramethylbenzidine (Zymed) was added. After 20 min, the reaction was stopped by adding $\mathrm{H}_{2} \mathrm{SO}_{4}$. Absorbance was measured at $450 \mathrm{~nm}$ using an ELISA SR 400 microplate reader (Sclavo, Siena, Italy). Sensitivity limit was $18 \mathrm{pg} / \mathrm{mL}$. Intra- and interassay coefficients of variation (CV\%) were 3.86 $\pm 0.95 \%$ and $9.14 \pm 0.47 \%$, respectively.

Immunohistochemistry. Immunohistochemistry of MIF in lipid layer preparations was performed using the streptavidinbiotin method as described (21). Lipid layer samples centrifuged onto glass slides were rehydrated and washed in TBS [20 $\mathrm{mM}$ Tris- $\mathrm{HCl}, 150 \mathrm{mM} \mathrm{NaCl}$ (pH 7.6)]. Antigen retrieval was performed by incubating slides in $10 \mathrm{mM}$ sodium citrate buffer, $\mathrm{pH} 6.0$, in a microwave oven at $750 \mathrm{~W}$ for $5 \mathrm{~min}$. Slides were preincubated with normal rabbit serum to prevent nonspecific binding, and incubated overnight at $4{ }^{\circ} \mathrm{C}$ with the anti-human MIF goat polyclonal antibody diluted 1:300 in TBS. Slides were then washed three times with TBS for $5 \mathrm{~min}$, and incubated with a rabbit anti-goat antibody labeled with biotin (Dako, Copenhagen, Denmark) at the dilution of 1:500 for 30 $\mathrm{min}$. The reaction was revealed using the streptavidin-biotin complex (Dako). Slides were mounted and examined under a light microscope. For each case, a negative control was obtained by replacing the specific antibody with nonimmune serum immunoglobulins at the same concentration as the primary antibody. As positive control, the reaction was performed on first-trimester human trophoblasts (21).

Data analysis. MIF concentrations in milk and serum samples are expressed as median [interquartile range, 25th-75th percentiles]. The paired Wilcoxon test was used for comparison. The relationship between milk and serum MIF concentra- 
tions and between milk aqueous phase and MFG aqueous phase MIF concentrations were assessed using univariate linear regression. A two-sided $p<0.05$ was considered to be statistically significant.

\section{RESULTS}

The presence of MIF in human milk and in milk fractions was first evaluated by immunoblotting. Samples of milk were run on SDS-PAGE and transferred to nitrocellulose. The blot was exposed to the anti-human MIF antibody, and bands were visualized by chemiluminescence. A single band with an apparent molecular weight of $12 \mathrm{kD}$ was observed in the samples analyzed (Fig. 1). When immunoblotting was used after twodimensional gel electrophoresis, two immunoreactive spots of a molecular weight of $12 \mathrm{kD}$ and $\mathrm{pI}$ of 6.98 and 7.8 were observed (Fig. 2), with the latter being the most represented and the nearest to the theoretical $\mathrm{pI}$ value of 8.24 predicted from MIF sequence in Swiss-Prot database.

The distribution of MIF in different fractions of milk was then assessed. To maintain the same protein ratio of the unprocessed milk, the pellet, the aqueous phase, and the lipid layer obtained by centrifugation were readjusted to the initial sample volume. As shown in Figure 3, MIF was present in the milk lipid layer (lane 3 ) and milk aqueous phase (lane 4). In the samples examined, the intensity of the band was always stronger in the lipid layer compartment. Pellet MIF did not appear to contribute to the immunoreactive band of the total milk, possibly because the pellet is only a small part of the milk volume. In the fractions obtained by processing the lipid layer, MFGM, and MFG aqueous and fat phases, an intense band corresponding in size to MIF was observed only in the MFG aqueous phase (lane 7). The localization of MIF in the milk lipid layer was then examined by immunohistochemistry. Figure 4 shows an image of an unprocessed milk lipid layer stained with the anti-MIF antibody. Immunoreactivity is con-

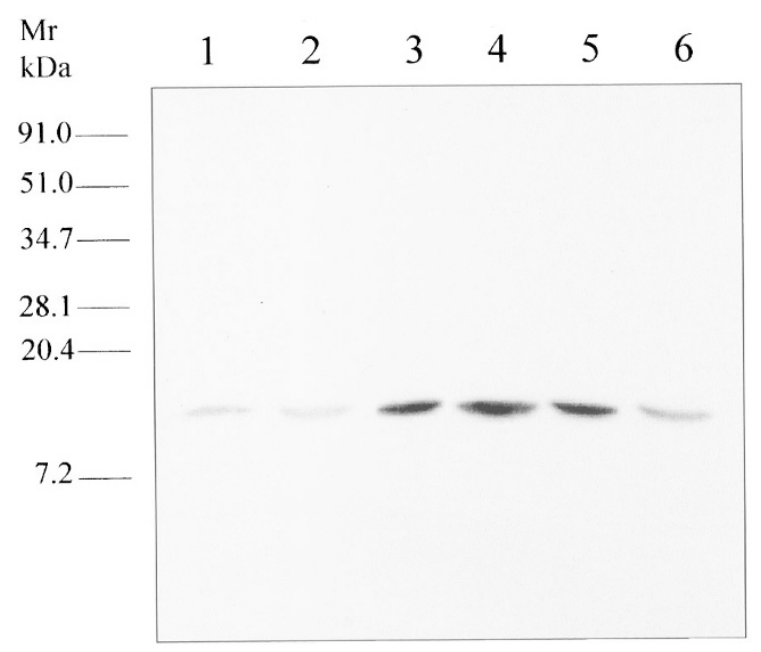

Figure 1. Representative Western blot profile of specimens of human milk, each from a different subject. Twenty micrograms of total protein were resolved by SDS-PAGE, transferred to nitrocellulose, and exposed to an anti-MIF antibody. The positions of molecular weight markers are indicated. Lanes 1-6, specimens of human milk.

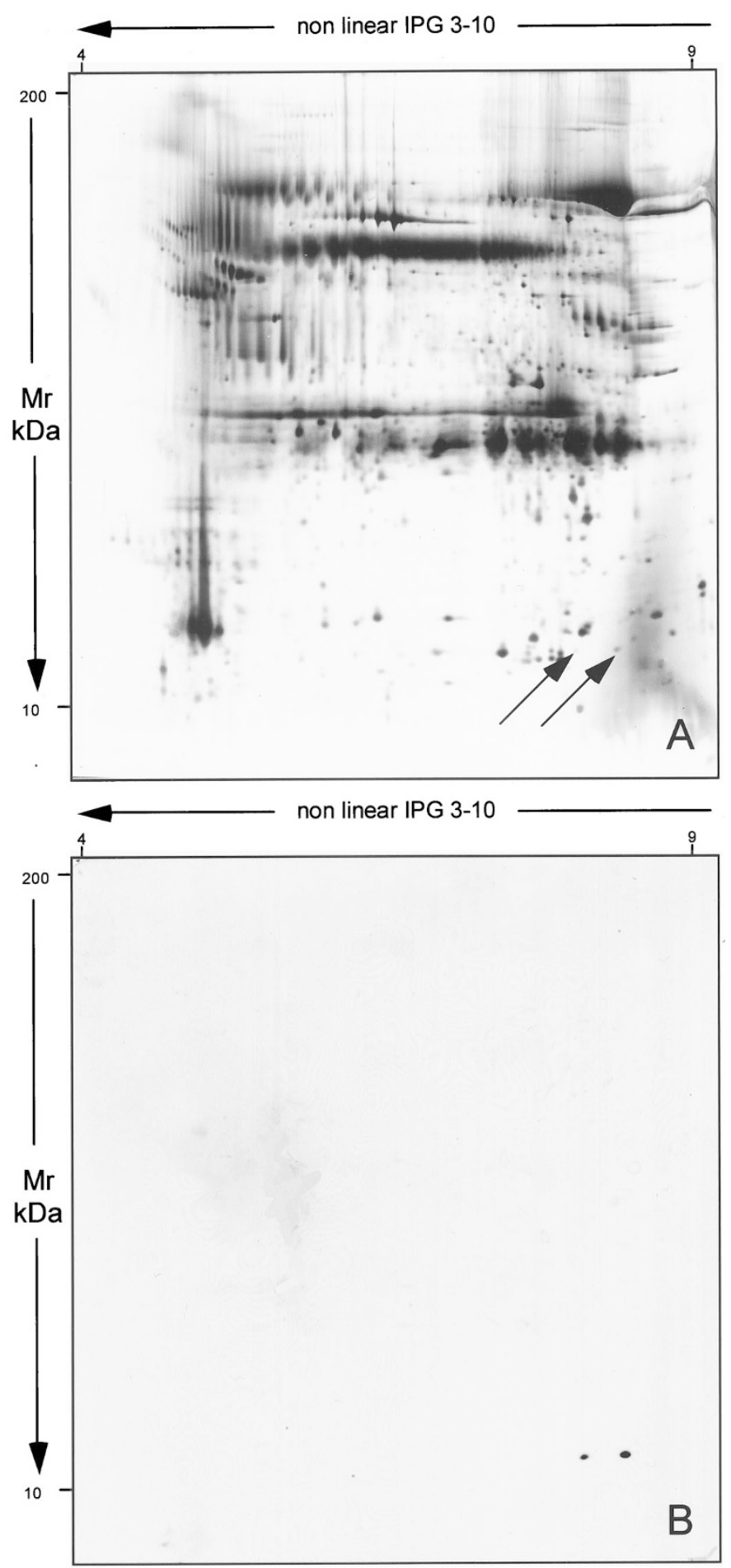

Figure 2. Identification of MIF in human milk by two-dimensional PAGE and Western blot. $A, 45 \mu \mathrm{g}$ of milk proteins was separated on a nonlinear immobilized $\mathrm{pH}$ gradient (IPG) gel strip (pH 3-10) for the first dimension. Acrylamide gradient gel $(9-16.5 \%)$ was run as second dimension and the gel stained with silver. $B, 90 \mu \mathrm{g}$ of proteins from the same sample was separated as above and transferred to a nitrocellulose membrane. The polyclonal antihuman MIF antibody identified in the blot as two isoforms, indicated with arrows in the top panel.

sistently found as a rim beneath the plasma membrane of the fat globule.

To determine the contribution of circulating MIF to the milk cytokine level, MIF concentrations were measured in a total of 


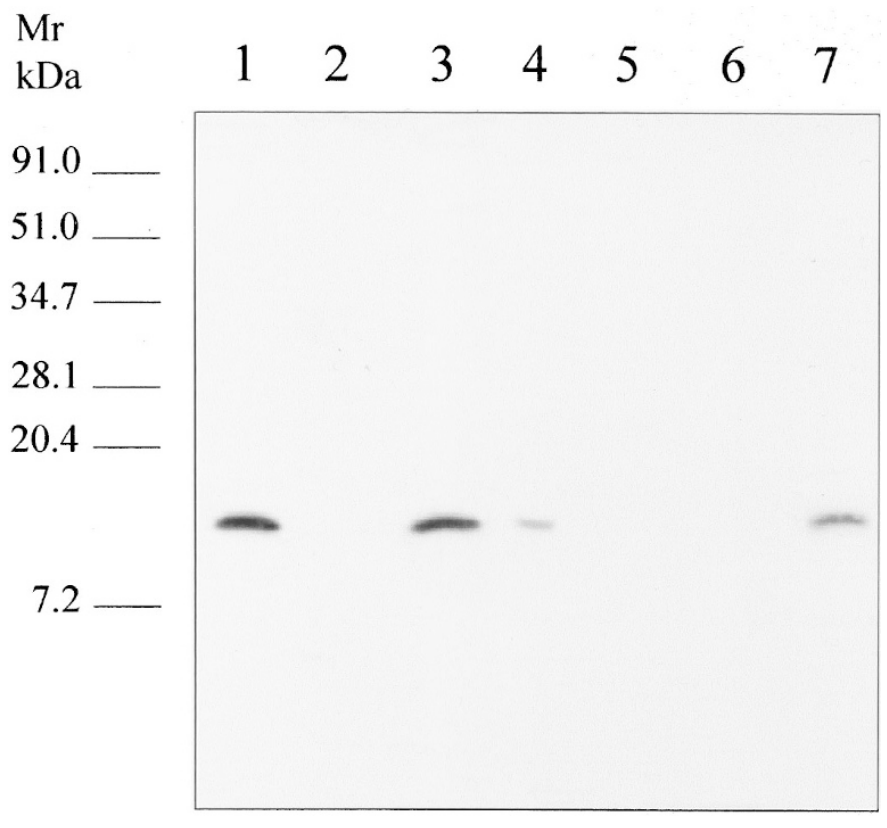

Figure 3. Western blot analysis of fractions of human milk. Proteins were resolved on a $16 \%$ SDS-PAGE, transferred to nitrocellulose, and analyzed with the anti-human MIF antibody. The positions of molecular weight markers are indicated. Samples of unprocessed milk (lane 1), pellet (lane 2), lipid layer (lane 3), aqueous phase (lane 4), MFGM (lane 5), lipid phase (lane 6), and MFG aqueous phase (lane 7) are shown.

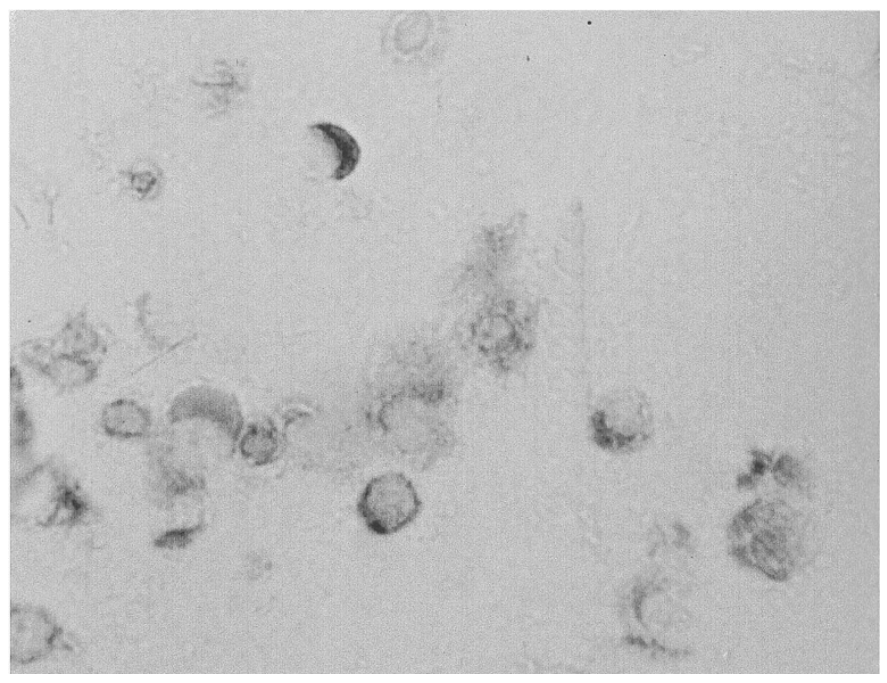

Figure 4. Immunolocalization of MIF in MFG. Milk lipid layer samples centrifuged onto glass slides were analyzed by immunohistochemistry using the streptavidin-biotin method (original magnification, $\times 1000$ ).

10 milk and blood serum samples. As shown in Figure 5, MIF concentration in milk aqueous phase, expressed as nanograms per milliliter, was found to be approximately 7.5-fold higher than serum (38.29; interquartile range, 25.32-55.69; value range, 9.72-79.51 versus 5.13; interquartile range, 4.78-5.40; value range, $4.02-5.78 ; T=55.0 ; p<0.001)$. No significant correlation was found between milk aqueous phase and serum MIF concentrations $\left(r^{2}=0.0041 ; p=0.86\right)$.

To quantify the distribution of MIF in the aqueous and lipid phases of milk, the milk aqueous phase and the MFG aqueous phase, both readjusted to the specimen starting volume, were

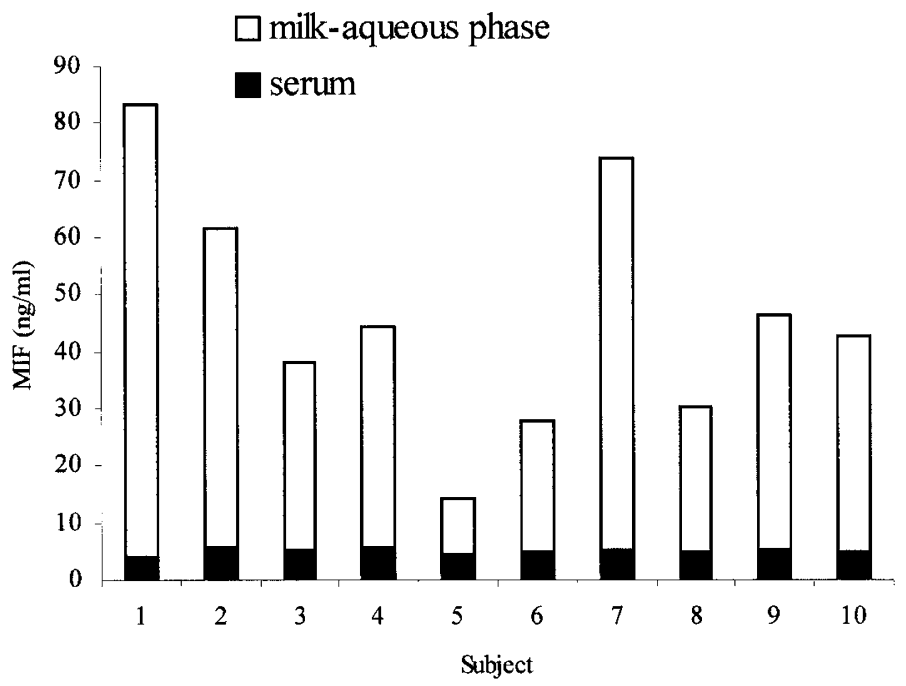

Figure 5. MIF concentration in milk aqueous phase $(n=10$; white bars $)$ and paired blood serum (black bars). Samples were assessed by ELISA. Data, expressed as nanograms per milliliter, are reported as the mean of two assays. No significant correlation was found between milk and serum MIF concentrations $\left(r^{2}=0.0041 ; p=0.86\right)$.

assayed. MIF concentration, was found to be approximately 2 -fold higher in MFG aqueous phase than in the milk aqueous phase in examined samples (73.07; interquartile range, 48.15146.33; value range, 15.41-231.16 versus 35.96 ; interquartile range, 31.81-55.68; value range, 31.81-55.68; $T=30.0 ; p=$ 0.12 ). No significant correlation was found between milk and MFG aqueous phase MIF concentrations $\left(r^{2}=0.54 ; p=\right.$ 0.088; Fig. 6).

\section{DISCUSSION}

Breast-feeding is a natural means of administration of cytokines to offspring, occurring when the immune system is immature and still developing (34). During this time, the newborn is adjusting to the external environment, establishing a bacterial flora in the oral cavity, gut, and upper respiratory tract. Although direct evidence is not yet available, orally administered cytokines are thought to modulate immune functions through activation of the mucosal and lymphoid cells of the oropharyngeal and gut-associated lymphoid tissue $(35,36)$. It is still unclear, however, how milk cytokines can avoid inactivation and retain their biologic activity through the gastrointestinal tract. Human milk contains factors limiting proteolysis $(37,38)$ or increasing the $\mathrm{pH}$ of the stomach, thereby protecting cytokines from degradation after exposure to gastric secretion (39). Compartmentalization in different fractions of human milk has also been suggested as an additional mechanism of protection (2). Thus, Garofalo et al. (8) showed that IL-10 is present in both the lipid layer and the aqueous phase of human milk. These authors speculated that the lipid phase could protect the cytokine during the transit through of the newborn gastrointestinal tract until it is released by the action of the bile salts in the duodenum. The current study is the first to describe the presence of MIF in human milk. This cytokine was found in high concentrations in the milk aqueous phase and in the lipid layer (compared with serum), in the latter 
$\square$ MFG-aqueous phase milk-aqueous phase

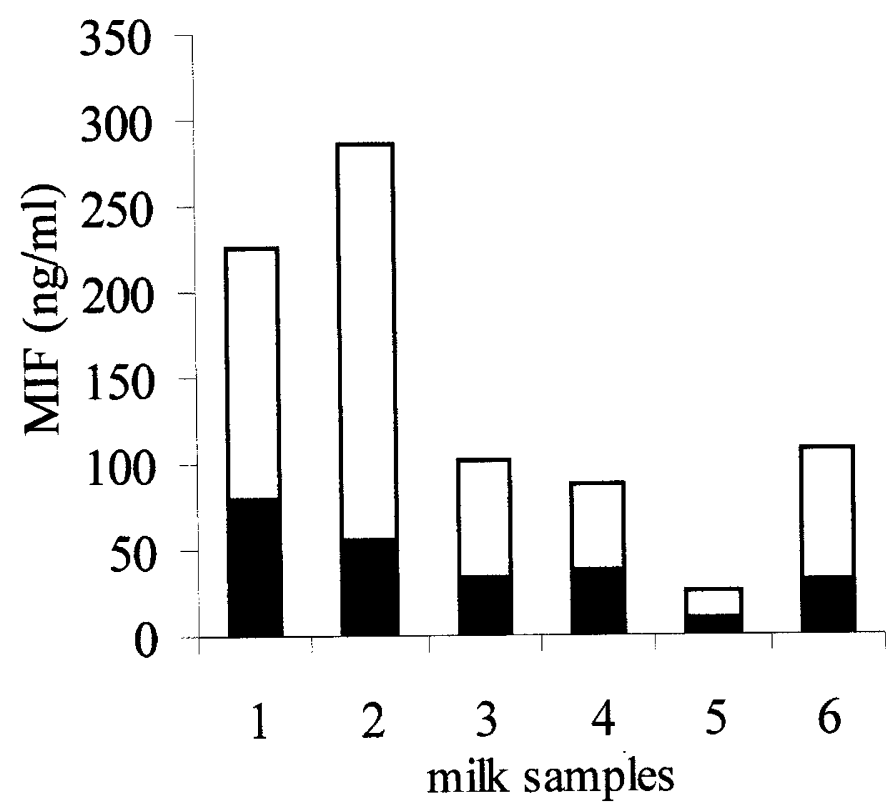

Figure 6. MIF in milk aqueous phase $(n=6$; black bars) and paired MFG aqueous phase (white bars). Samples were assessed by ELISA. Data are expressed as nanograms per milliliter of total milk. Values are reported as the mean of two assays. No significant correlation was found between milk and MFG aqueous phase MIF concentrations $\left(r^{2}=0.54 ; p=0.088\right)$.

essentially localized inside the fat globules. Moreover, immunohistochemical analysis of unprocessed lipid layer revealed MIF immunoreactivity inside the MFG, localized in a gap between the core fat and the surrounding membrane. Taken together, these data represent the first direct evidence of cytokine compartmentalization in human milk, thus revealing a novel strategy for the protection of milk cytokines during the transit through the newborn gastrointestinal tract.

Besides being localized inside the MFG, MIF was also consistently found in the milk aqueous phase. This finding supports the existence of an alternative mechanism of release of this cytokine by breast epithelial cells. Several other studies demonstrated that MIF, despite the lack of an $\mathrm{NH}_{2}$-terminal signal sequence, is actively secreted by a variety of cell types (40). In this context, the observation of Nishino and colleagues (23) that localized MIF to the secretory granules of ACTH- and TSH-secreting cells of the pituitary gland is of relevance. In the epithelial cells of lactating mammary gland, cytoplasmic lipid globules are surrounded by secretory vesicles, which fuse to form large membrane-bound compartments around the fat globule (41). Such secretory vesicle-surrounded fat vacuoles ascend to the secretory apex, and before detachment of the apical portion of the cell occurs, the secretory compartment fuses with the plasma membrane (42). It appears therefore conceivable that after this process, secretory MIF-containing vesicles would be finally released into the glandular lumen. Unlike the lipid layer MIF, which might exert its function on the distal portions of the newborn gastrointestinal tract, the aqueous phase MIF could mainly target the oropharyngeal lymphoid system. Furthermore, additional biologic roles can be suggested for the soluble cytokine, in consideration of the specific actions exerted by MIF on macrophages $(43,44)$. It is well known, in fact, that human milk contains an abundant leukocyte population of which macrophages represent a major cellular component (1). These cells, migrating from the maternal circulation into the breast milk (45), are known to protect the breast-fed infant against infectious diseases by virtue of their antimicrobial activity (46). In addition, as proposed for the nonlactating mammary gland (47), macrophages in the lactating breast tissue may play an important role by cleaning up ducts and removing cell debris.

Previous studies described the presence in human milk of cytokines with well-defined functions in promoting monocyte migration and activation (granulocyte colony-stimulating factor, macrophage colony-stimulating factor, and granulocytemacrophage colony-stimulating factor) (9-11). Nevertheless, the mechanisms involved in maintaining macrophage population in the lactating mammary gland are not fully defined. Macrophages are the main target of MIF, which acts on these cells by inhibiting migration and enhancing their phagocytic activity. Hence, it is speculated that milk MIF, by affecting macrophage accumulation and activation, may play an important role in the physiologic activity of the mammary gland. Further studies evaluating the effects of MIF neutralizing antibodies on the migration and phagocytic activity of milk macrophages in vitro are needed to confirm this hypothesis.

Acknowledgment. The authors thank Prof. V. Bocci for his critical review of the manuscript and suggestions.

\section{REFERENCES}

1. Goldman AS 1993 The immune system of human milk: antimicrobial, antiinflammatory and immunomodulating properties. Pediatr Infect Dis J 12:664-672

2. Garofalo RP Goldman AS 1998 Cytokines, chemokines, and colony-stimulating factors in human milk: the 1997 update. Biol Neonate 74:134-142

3. Rudloff HE, Schmalstieg FC Jr, Mushtaha AA, Kimberly H, Palkowetz KH, Liu SK, Goldman AS 1992 Tumor necrosis factor- $\alpha$ in human milk. Pediatr Res 31:29-33

4. Munoz C, Endres S, van der Meer J, Schlesinger L, Arevalo M, Dinarello C 1990 Interleukin-1 $\beta$ in human colostrum. Res Immunol 141:503-513

5. Bocci V, Von Bremen K, Corradeschi F, Franchi F, Luzzi E, Paulesu L 1993 Presence of interferon- $\gamma$ and interleukin- 6 in colostrum of normal women. Lymphokine Cytokine Res 12:21-24

6. Bryan D-L, Hawkes JS, Gibson RA 1999 Interleukin-12 in human milk. Pediatr Res 45:858-859

7. Srivastava MD, Srivastava A, Brouhard B, Saneto R, Groh-Wargo S, Kubit J 1996 Cytokines in human milk. Res Commun Mol Pathol Pharmacol 93:263-287

8. Garofalo R, Chheda S, Mei F, Palkowetz KH, Rudloff HE, Schmalstieg FC, Rassin DK, Goldman AS 1995 Interleukin-10 in human milk. Pediatr Res 37:444-449

9. Gasparoni A, Chirico G, De Amici M, Ravagni-Probizer MF, Ciardelli L, Marchesi ME, Rondini G 1996 Granulocyte-macrophage colony-stimulating factor in human milk. [letter] Eur J Pediatr 155:69

10. Hara T, Irie K, Saito S, Ichijo M, Yamada M, Yanai N, Miyazaki S 1995 Identification of macrophage colony-stimulating factor in human milk and mammary gland epithelial cells. Pediatr Res 37:437-443

11. Calhoun DA, LunØe M, Du Y, Christensen RD 2000 Granulocyte colony-stimulating factor is present in human milk and its receptor is present in human fetal intestine. Pediatrics 105:392-397

12. Bloom BR, Bennett B 1966 Mechanism of reaction in vitro associated with delayedtype hypersensitivity. Science 153:80-82

13. Calandra T, Bernhagen J, Mitchell RA, Bucala R 1994 The macrophage is an important and previously unrecognized source of macrophage migration inhibitory factor. J Exp Med 179:1895-1902

14. Bernhagen J, Calandra T, Mitchell RA, Martin SB, Tracey KJ, Voelter W, Manogue KR, Cerami A, Bucala R 1993 MIF is a pituitary-derived cytokine that potentiates lethal endotoxaemia. Nature 365:756-759

15. Calandra T, Bernhagen J, Metz CN, Spiegel LA, Bacher M, Donnelly T, Cerami A, Bucala R 1995 MIF as a glucocorticoid-induced modulator of cytokine production. Nature 377:68-71 
16. Wistow GJ, Shaughnessy MP, Lee DC, Hodin J, Zelanka PS 1993 A macrophage migration inhibitory factor is expressed in the differentiating cells of the eye lens. Proc Natl Acad Sci USA 90:1272-1275

17. Matsuda A, Tagawa Y, Matsuda H, Nishihira J 1996 Identification and immunological localization of macrophage migration inhibitory factor in human cornea. FEBS Lett 385:225-228

18. Shimizu H, Ohkawara A, Nishihira J, Sakamoto W 1996 Identification of macrophage migration inhibitory factor (MIF) in human skin and its immunohistochemical localization. FEBS Lett 381:199-202

19. Imamura K, Nishihira J, Suzuki M, Yasuda K, Sasaki S, Kusunoki Y, Tochimaru H, Takekoshi Y 1996 Identification and immunohistochemical localization of macrophage migration inhibitory factor in human kidney. Biochem Mol Biol Int 40:12331242

20. Magi B, Bini L, Liberatori S, Marzocchi B, Raggiaschi R, Arcuri F, Tripodi SA, Cintorino M, Tosi P, Pallini V 1998 Charge heterogeneity of macrophage migration inhibitory factor (MIF) in human liver and breast tissue. Electrophoresis 19:20102013

21. Arcuri F, Cintorino M, Vatti R, Carducci A, Liberatori S, Paulesu L 1999 Expression of macrophage migration inhibitory factor transcript and protein by first trimester human trophoblasts. Biol Reprod 60:1299-1303

22. Arcuri F, Ricci C, Ietta F, Cintorino M, Tripodi S, Cetin I, Garzia E, Shatz F, Klemi P, Santopietro R, Paulesu L 2001 Macrophage migration inhibitory factor in the human endometrium: expression and localization during the menstrual cycle and early pregnancy. Biol Reprod 64:1200-1205

23. Nishino T, Bernhagen J, Shiiki H, Calandra T, Dohi K, Bucala R 1995 Localization of macrophage migration inhibitory factor (MIF) to secretory granules within the corticotrophic and thyrotrophic cells of the pituitary gland. Mol Med 1:781-788

24. Hirokawa J, Sakaue S, Tagami S, Kawakami Y, Sakai M, Nishi S, Nishihira J 1997 Identification of macrophage migration inhibitory factor in adipose tissue and its induction by tumor necrosis factor- $\alpha$. Biochem Biophys Res Commun 235:94-98

25. Meinhardt A, Bacher M, Wennemuth G, Eickhoff R, Hedger M 2000 Macrophage migration inhibitory factor (MIF) as a paracrine mediator in the interaction of testicular somatic cells. Andrologia 32:46-48

26. Arcuri F, Del Vecchio MT, De Santi MM, Lalinga AV, Pallini V, Bini L, Bartolommei S, Parigi S, Cintorino M 1999 Macrophage migration inhibitory factor in the human prostate: identification and immunocytochemical localization. Prostate 39:159-165

27. Basch JJ, Greenberg R, Farrell Jr HM 1985 Identification of the milk fat globule membrane proteins. II. Isolation of major proteins from electrophoretic gels and comparison of their amino acid compositions. Biochim Biophys Acta 830:127-135

28. Laemmli UK 1970 Cleavage of structural proteins during the assembly of the head of bacteriophage T4. Nature 227:680-685

29. Bradford MM 1976 A rapid and sensitive method for the quantification of microgram quantities of protein utilizing the principle of protein-dye binding. Anal Biochem $72: 248-254$
30. Görg A, Postel W, Gunther S 1988 The current state of two-dimensional electrophoresis with immobilized $\mathrm{pH}$ gradients. Electrophoresis 9:531-546

31. Bjellqvist B, Pasquali C, Ravier F, Sanchez JC, Hochstrasser D 1993 A nonlinear wide-range immobilized $\mathrm{pH}$ gradient for two-dimensional electrophoresis and its definition in a relevant $\mathrm{pH}$ scale. Electrophoresis 14:1357-1365

32. Hochstrasser DF, Harrington MG, Hochstrasser AC, Miller MJ, Merril CR 1988 Methods for increasing the resolution of two-dimensional protein electrophoresis. Anal Biochem 173:424-435

33. Towbin H, Staehelin T, Gordon J 1979 Electrophoretic transfer of proteins from polyacrylamide gels to nitrocellulose sheets: procedure and some applications. Proc Natl Acad Sci USA 76:4350-4354

34. Bocci V, Von Bremen K, Corradeschi F, Luzzi E, Paulesu L 1991 What is the role of cytokines in the human colostrum? J Biol Regul Homeost Agent 5:121-124

35. Bocci V 1999 The oropharyngeal delivery of interferons: where are we and where do we need to go? J Interferon Cytokine Res 19:859-861

36. Fleischmann WR, Koren S 1999 Systemic effects of orally administered interferons and interleukin-2. J Interferon Cytokine Res 19:829-839

37. Goldman AS, Chheda S, Garofalo R, Schmalstieg FC 1996 Cytokines in human milk: properties and potential effects upon the mammary gland and the neonate. J Mammary Gland Biol Neoplasia 1:251-258

38. Juul SE, Zhao Y, Dame JB, Du Y, Hutson AD, Christensen RD 2000 Origin and fate of erythropoietin in human milk. Pediatr Res 48:660-667

39. Calhoun DA, LunØe M, Du Y, Staba SL, Christensen RD 1999 Concentrations of granulocyte colony-stimulating factor in human milk after in vitro simulation of digestion. Pediatr Res 46:767-771

40. Swope MD, Lolis E 1999 Macrophage migration inhibitory factor: cytokine, hormone, or enzyme? Rev Physiol Biochem Pharmacol 139:1-32

41. Metka K, Nada P 1992 The role of exocytosis in the apocrine secretion of milk lipid globules in mouse mammary gland during lactogenesis. Biol Cell 75:211-216

42. Wu CC, Howell KE, Neville MC, Yates III JR, McManaman JL 2000 Proteomics reveal a link between the endoplasmic reticulum and lipid secretory mechanisms in mammary epithelial cells. Electrophoresis 21:3470-3482

43. Onodera S, Suzuki K, Matsuno T, Kaneda K, Takagi M, Nishihira J 1997 Macrophage migration inhibitory factor induces phagocytosis of foreign particles by macrophages in autocrine and paracrine fashion. Immunology 92:131-137

44. Weiser WY, Pozzi LM, David JR 1991 Human recombinant migration inhibitory factor activates human macrophages to kill Leishmania donovani. J Immunol 147:2006-2011

45. Michie CA, Tantscher E, Schall T, Rot A 1998 Physiological secretion of chemokines in human breast milk. Eur Cytokine Netw 9:123-129

46. Ho PC, Lawton JW 1978 Human colostral cells: phagocytosis and killing of E. coli and C. albicans. J Pediatr 93:910-915

47. Dabbs DJ 1993 Mammary ductal foam cells: macrophage immunophenotype. Hum Pathol 24:977-981 